\title{
BMJ Open The role of psychological factors in the perpetuation of pain intensity and disability in people with chronic shoulder pain: a systematic review
}

To cite: Martinez-Calderon J, Meeus M, Struyf F, et al. The role of psychological factors in the perpetuation of pain intensity and disability in people with chronic shoulder pain: a systematic review. BMJ Open 2018;8:e020703. doi:10.1136/ bmjopen-2017-020703

- Prepublication history and additional material for this paper are available online. To view these files, please visit the journal online (http://dx.doi. org/10.1136/bmjopen-2017020703).

Received 21 November 2017 Revised 13 March 2018 Accepted 15 March 2018

Check for updates

${ }^{1}$ Department of Physiotherapy, University of Malaga, Malaga, Spain

${ }^{2}$ Department of Rehabilitation Sciences and Physiotherapy, University of Antwerp, Antwerp, Belgium

${ }^{3}$ Rehabilitation Sciences and Physiotherapy Department, Ghent University, Ghent, Belgium

${ }^{4}$ Pain in Motion International

Research Group

${ }^{5}$ Department of Nursing,

University of Malaga, Malaga,

Spain

${ }^{6}$ Department of Nursing and Podiatry, University of Malaga, Malaga, Spain

Correspondence to Javier Martinez-Calderon; calderonjmc@uma.es

\section{ABSTRACT}

Introduction Chronic shoulder pain is a very complex syndrome, and the mechanisms involved in its perpetuation remain unclear. Psychological factors appear to play a role in the perpetuation of symptoms in people with shoulder chronicity. The purpose of this systematic review is to examine the role of psychological factors in the perpetuation of symptoms (pain intensity and disability) in people with chronic shoulder pain.

Methods and analysis A systematic search was performed on PubMed, AMED, CINAHL, PubPsych and EMBASE from inception to July 2017. Longitudinal studies with quantitative designs analysing the role of psychological factors on pain intensity, disability or both were included. The methodological quality of the included studies was evaluated with an adapted version of the Newcastle Ottawa Scale. The level of evidence per outcome was examined using the Grading of Recommendations Assessment, Development and Evaluation approach.

Results A total of 27 articles were included with a sample of 11176 people with chronic shoulder pain. The risk of bias ranges from 7/21 to $13 / 21$ across the studies. The quality of the evidence was very low. High levels of self-efficacy, resilience and expectations of recovery were significantly associated with low levels of pain intensity and disability. Inversely, high levels of emotional distress, depressive symptoms, anxiety, preoperative concerns, fear-avoidance beliefs, somatisation and pain catastrophising were significantly associated with high levels of pain intensity and disability.

Discussion Our results suggest that psychological factors may influence the perpetuation of pain intensity and disability, with very low evidence. A meta-analysis was not carried out due to the heterogeneity of the included studies so results should be interpreted with caution.

PROSPERO trial registration number CRD42016036366.

\section{INTRODUCTION}

Chronic shoulder pain (CSP) is very common in both the general ${ }^{1}$ and the working population. ${ }^{2}$ The prevalence and the socioeconomic impact of CSP is high. ${ }^{3}$ It ranges from $1 \%$ to $67 \%$ across different populations. ${ }^{4}$
Strengths and limitations of this study

- The use of a prespecified protocol registered on the International Prospective Register of Systematic Reviews, the Preferred Reporting Items for Systematic Reviews and Meta-Analyses checklist, the Grading of Recommendations Assessment, Development and Evaluation approach to evaluate the overall quality and the strength of the evidence, and the adapted Newcastle Ottawa Scale to determine the risk of bias in each study.

- It is possible that some studies were not identified even though both a comprehensive and a robust search strategy were carried out.

- Reported bias was found in several included studies.

The quality of the evidence was very low.

The results of the present study are not robust, and conclusions should be interpreted with caution.

People with CSP report a broad variability in symptoms such as pain, insomnia and/or disability. ${ }^{3}$ Personal, occupational, psychological, social and biological factors have been associated with the delay in recovery from CSP. ${ }^{45}$ CSP is a very complex syndrome, and the mechanisms involved in its perpetuation remain unclear. Indeed, recovery rates are poor, with roughly $60 \%$ of patients with CSP reporting persistence of symptoms 12 months after onset. ${ }^{6}$

Contemporary approaches, from a biopsychosocial perspective, have emerged to analyse why many people do not recover after an acute episode of pain. ${ }^{7-9}$ In this context, psychological factors seem to play a key role in the explanation as to why musculoskeletal pain becomes chronic, once the tissue damage has healed. ${ }^{10-13}$ Over the last decades, the fear-avoidance (FA) model of pain has been largely explored. ${ }^{14-16}$ When it is specifically applied to musculoskeletal pain, ${ }^{15}$ it proposes that people who have musculoskeletal pain and a trait tendency to have 
fearful and catastrophic thoughts, have a greater likelihood of developing chronic pain. The model conveys how people who perceive pain as a threat, often exhibit protective behaviours (eg, hypervigilance) in order to prevent a potential new injury/re-injury. ${ }^{15}$ In the acute stage of the recovery process, these behaviours can be adaptive. ${ }^{17}$ However, they become maladaptive once pain remains for a long time. ${ }^{18}$ This unsuitable confrontation of the pain experience leads to a greater disuse of the affected area, causing physical and psychological consequences which provoke more pain and disability. ${ }^{18} \mathrm{In}$ this stage, all aspects involving fear (pain-related fear, kinesiophobia, hypervigilance and pain catastrophising) are intensified. This vicious cycle directly interferes in the person's recovery, which reduces treatment adherence and preserves the negative pain experience. ${ }^{14}$ Inversely, people with musculoskeletal pain who report high levels of psychological factors, which are thought to be protective (eg, self-efficacy), are presumed to manage their pain better and, therefore, have a greater chance for recovery. ${ }^{11}$

The role of psychological factors on pain intensity and disability in people with CSP has been evaluated. ${ }^{20-25}$ The findings of these studies have shown a possible relationship between the factors and the outcomes previously mentioned. People with CSP who mismanage their pain experience may create a negative spiral of pain perception, which could mean healing delays, brain alterations ${ }^{26}$ and cognitive-behavioural changes. ${ }^{27}$ Therefore, research efforts need to be focused on obtaining more knowledge and understanding about how psychological factors are associated with a poor or better prognosis in people with CSP. This understanding is crucial to acquire a clear picture of the process involved in CSP. This may aid in improving the current poor prognosis of this condition. To our knowledge, this is the first synthesis of evidence that explores the role of psychological factors on pain intensity and disability in people with CSP. A systematic review may help to diminish the uncertainty caused by the heterogeneity of particular studies, and may permit the formation of firm conclusions through an exhaustive synthesis of data. ${ }^{28}$ Hence, the aim of this study was to answer the following PECOS (P, participant; E, exposure; $\mathrm{C}$, comparator; $\mathrm{O}$, outcome; $\mathrm{S}$, study design) question through a systematic review of the literature on longitudinal studies (S): which is the role of psychological factors $(\mathrm{E})$ on pain intensity and disability $(\mathrm{O})$ in people with $\operatorname{CSP}(\mathrm{P})$ ?

\section{MATERIALS AND METHODS}

This systematic review was conducted in accordance with the Preferred Reporting Items for Systematic Reviews and Meta-Analyses (PRISMA) statement. ${ }^{29}$ The abstract was carried out using the PRISMA reporting guidelines for abstracts (http://www.prisma-statement.org/Extensions/Abstracts.aspx). The systematic review protocol was registered at the International Prospective Register of Systematic Reviews (PROSPERO: CRD42016036366).
Patient and public involvement

Patients and or public were not involved.

\section{Data sources and search strategy}

A systematic search was performed by two independent reviewers (JM-C and AL-S) from inception to August 2016 using optimised search strategies in the following electronic databases: PubMed, AMED, CINAHL, PubPsych and EMBASE. An update of the search strategy was carried out on July 2017. A manual search of relevant eligible studies, to select any studies missed during the electronic search, was also carried out using cross-references identified both in journals associated with the topic of this review, and in reference lists within both original and review articles. A sensitive search strategy using relevant search terms that were developed from Medical Subject Headings (MeSH), and keywords generated from the subject headings, as follows: 'chronic pain' (MeSH Terms), 'surgery' (MeSH Terms), 'arthroscopy' (MeSH Terms), 'shoulder pain' (MeSH Terms), 'rotator cuff' (MeSH Terms), 'fear' (MeSH Terms), 'catastrophization' (MeSH Terms), 'depression' (MeSH Terms), 'anxiety' (MeSH Terms), 'self-efficacy' (MeSH Terms), adhesive capsulitis, frozen shoulder, psychological factors, kinesiophobia, coping, expectations, were used. The complete search strategy report is shown in online supplementary appendix A. The grey literature, such as NHS Evidence, New York Academy of Medicine Grey Literature Report, Grey Source, Open Grey and Google Scholar ${ }^{30}$ were explored to detect any relevant unpublished work. To gather any other non-published data, researchers were contacted directly. References were exported, and duplicates were removed using citation management software (Mendeley desktop V.1.17.4).

\section{Eligibility criteria}

The aforementioned PECOS framework was followed to determine which studies were included in the present systematic review. Each study had to meet the following inclusion criteria:

i. Longitudinal studies (prospective and retrospective) (S) examining the role of psychological factors $(\mathrm{E})$ on pain intensity, disability or both $(\mathrm{O})$ in people with CSP $(\mathrm{P})$. Studies with a non-exposed cohort $(\mathrm{C})$ in order to satisfy all the PECOS criteria. However, no included study reported a non-exposed cohort.

ii. Studies whose participants were adults diagnosed with CSP (>3 months).

iii. Studies written in English.

iv. No restriction was applied on the participants' gender or ethnicity.

v. Studies that reported a follow-up at least 6 weeks after intervention.

vi. Studies recruiting participants from any setting (general population, primary, secondary or tertiary care). 
vii. Studies providing at minimum an association between psychological factors and pain intensity, disability or both through a quantitative design.

The exclusion criteria were as follows:

i. All studies that did not include a longitudinal design (eg, cross-sectional studies).

ii. Studies exploring psychological factors in people with acute or subacute shoulder pain.

iii. Studies evaluating psychological factors in people with CSP due to spinal cord injury, stroke, rheumatoid arthritis or cancer.

iv. Studies aimed at modifying levels of psychological factors through any therapy.

v. Studies investigating the psychometric properties of psychological factor assessment measures.

\section{Study selection}

All studies identified by the search strategy were screened using our eligibility criteria. Two independent reviewers (JM-C and AL-S) carried out the first stage, which involved the screening of articles by title and abstract. The same reviewers undertook the second stage, screening the full text. In cases of disagreement, a decision was made by consensus or, when necessary, a third reviewer (JMM-A) was consulted. A short checklist was adapted to the present review in order to guide the selection of relevant studies (see online supplementary appendix B). ${ }^{31}$

\section{Data extraction}

Two independent reviewers (JM-C and AL-S) extracted the following relevant data from each study: study details (first author, year of publication), sample size, characteristics of participants (mean age, mean duration of symptoms), metric of psychological factor measures, metric of outcome (pain intensity and disability) measures, duration of follow-up and study design. If there was any discrepancy between reviewers, a third reviewer was consulted (JMM-A). When necessary, an email was sent to the original authors to provide further information on participants' data.

\section{Quality assessment}

Two independent reviewers (JM-C and AL-S) assessed the risk of bias of the included studies using the Newcastle Ottawa Scale (NOS). ${ }^{32}$ The NOS is a reliable and valid tool for assessing the quality of non-randomised studies. ${ }^{32}$ Due to none of the included studies used as non-exposed cohort, we decided to use an adapted version of the NOS, which was developed to evaluate the quality of any observational design. ${ }^{33}$ This adapted version has been used for previous systematic reviews ${ }^{33}$ and includes four domains of risk or bias assessment: methods for selecting study participants (selection bias), methods to control for confounding (performance bias), statistical methods (detection bias) and methods for exposure and outcome assessment (information bias). Seven items compose the four domains. Each item is scored from 0 (high risk) to 3 (low risk) points. Therefore, the maximum score for each study could be 21 points. To assess the overall quality and the strength of the evidence per outcome, the Grading of Recommendations Assessment, Development and Evaluation (GRADE) approach was used. ${ }^{34}$ In brief, the GRADE classification was carry out according to the presence, or not, of the following identified factors: (i) risk of bias, (ii) inconsistency of results, (iii) indirectness, (iv) imprecision and (v) other considerations (eg, reporting bias). Two reviewers (JM-C and AL-S) judged whether these factors were present for each outcome. The GRADE approach was only applied when at least the three studies informed of every outcome.

\section{Statistical analysis}

For the primary analysis, studies were grouped per outcome (pain intensity and disability). A meta-analysis could not be carried out as the heterogeneity was too high in terms of participant characteristics (mean age and duration of symptoms), sample size, metric of outcome measures, metric of psychological factor measures and statistical methods used in most of the potentially eligible studies. Consequently, a descriptive quantitative analysis (the most relevant summary measure with a precise estimate) was provided for every study. For the studies that reported results with several degrees of adjustment for confounders, in different models, the estimate was extracted from the model that showed the best adjustment. GRADEpro software, ${ }^{35}$ and Review Manager (RevMan) V.5.3 (Copenhagen: The Nordic Cochrane Centre, The Cochrane Collaboration, 2014) software were used to process data during the review.

\section{RESULTS}

\section{Study characteristics}

A total of 2697 citations were identified through electronic databases, with 17 additional studies identified through reference screening. The authors screened 896 titles and abstracts, with 128 full-text articles finally being evaluated. The number of studies retrieved from each database and the number of studies excluded in each screening phase are shown in figure 1. The full reference of excluded studies in the last screening $(\mathrm{n}=101)$ is reported in online supplementary appendix C. The conflict of interests of included studies is reported in online supplementary appendix D. A total of 27 longitudinal studies (18 prospective cohort studies; 6 retrospective cohort studies and 3 secondary data analyses) with a total of 11176 participants with CSP satisfied our inclusion criteria and were included in this review. Seventeen studies explored the role of psychological factors in people with CSP presurgery and postsurgery. ${ }^{20} 2136-50$ Ten studies evaluated this role in people with CSP without surgery. ${ }^{22-25} 51-56$ The outcome measures included in this review were pain intensity $^{2022232536-4446-56}$ and disability. ${ }^{20-2538-5456}$ The psychological factors were: depressive symptoms, ${ }^{22} 232537-414348-505255$ anxiety, $225363739-4143505255$ emotional distress, ${ }^{25434451525456}$ 

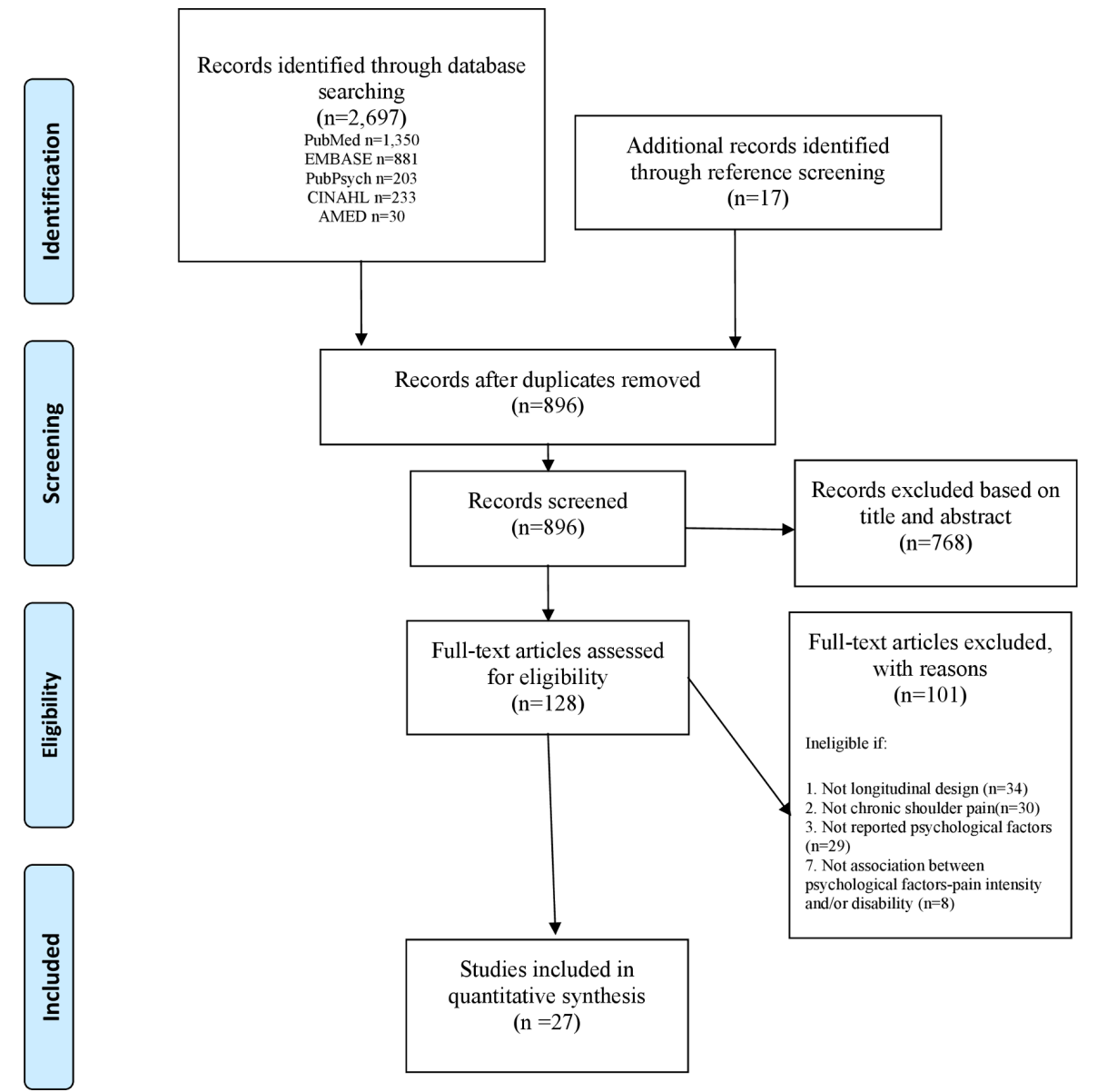

Figure 1 Flow diagram of review process. Adapated from Moher D, Liberati A, Tetzlaff $\mathrm{J}$, et al. Preferred reporting items for systematic review and meta-analyses: the PRISMA Statement. PLoS Med 2009;6:e1000097. For more information, visit www. prisma-statement.org

self-efficacy, ${ }^{22} 515455$ expectations of recovery, ${ }^{20-22} 42454651$ pain catastrophising, ${ }^{24} 2536-385355$ FA beliefs, ${ }^{24} 5355$ somatisation, ${ }^{25} 43$ fear of pain, ${ }^{36}$ kinesiophobia, ${ }^{36}$ optimism, ${ }^{53}$ pain acceptance,${ }^{55}$ preoperative concerns, ${ }^{21}$ sleep disturbances ${ }^{39}$ coping with pain, ${ }^{25}$ internal and external locus of control $^{25}$ and resilience. ${ }^{47}$ The characteristics of the included studies are reported in table 1.

\section{Methodological quality}

The degree to which studies met the quality criteria varied considerably, ranging from $7 / 21$ to $13 / 21$. The risk of bias assessment for the included studies is presented in table 2.

\section{The role of psychological factors in the perpetuation of symptoms (pain intensity and disability) in people with CSP}

After analysing the risk of bias for the included studies, the strength and the quality of the evidence for each outcome was determined using the GRADE approach. Since observational studies were included and methodological limitations, inconsistencies, indirectness of evidence, imprecisions of results and other issues were presented, a very low level of evidence was found for each outcome (table 3). A description of the statistical results is reported in table 4 for pain intensity and in table 5 for disability.

\section{The role of psychological factors on pain intensity in people with CSP without surgery}

The role of psychological factors on pain intensity in people with CSP without surgery was explored in 10 studies. ${ }^{222325}{ }^{51-56}$ High levels of self-efficacy ${ }^{2254}$ and expectations of recovery ${ }^{22}$ were significantly associated with low levels of pain intensity. High levels of emotional distress, ${ }^{54}$ depressive symptoms, ${ }^{22} 23$ anxiety, ${ }^{22}$ FA beliefs ${ }^{55}$ and pain catastrophising $^{25}$ were significantly associated with high levels of pain intensity. There was no statistical relationship between optimism, somatisation, coping with pain, internal and external locus of control or pain acceptance and pain intensity in people with CSP without surgery.

The role of psychological factors on pain intensity in people with CSP presurgery and postsurgery

The role of psychological factors on pain intensity in people with CSP presurgery and postsurgery was analysed in 15 studies. ${ }^{20}{ }^{36-44} 46-50$ High levels of resilience ${ }^{47}$ and preoperative expectations ${ }^{20} 46$ were significantly associated with low levels of pain intensity. High levels of 


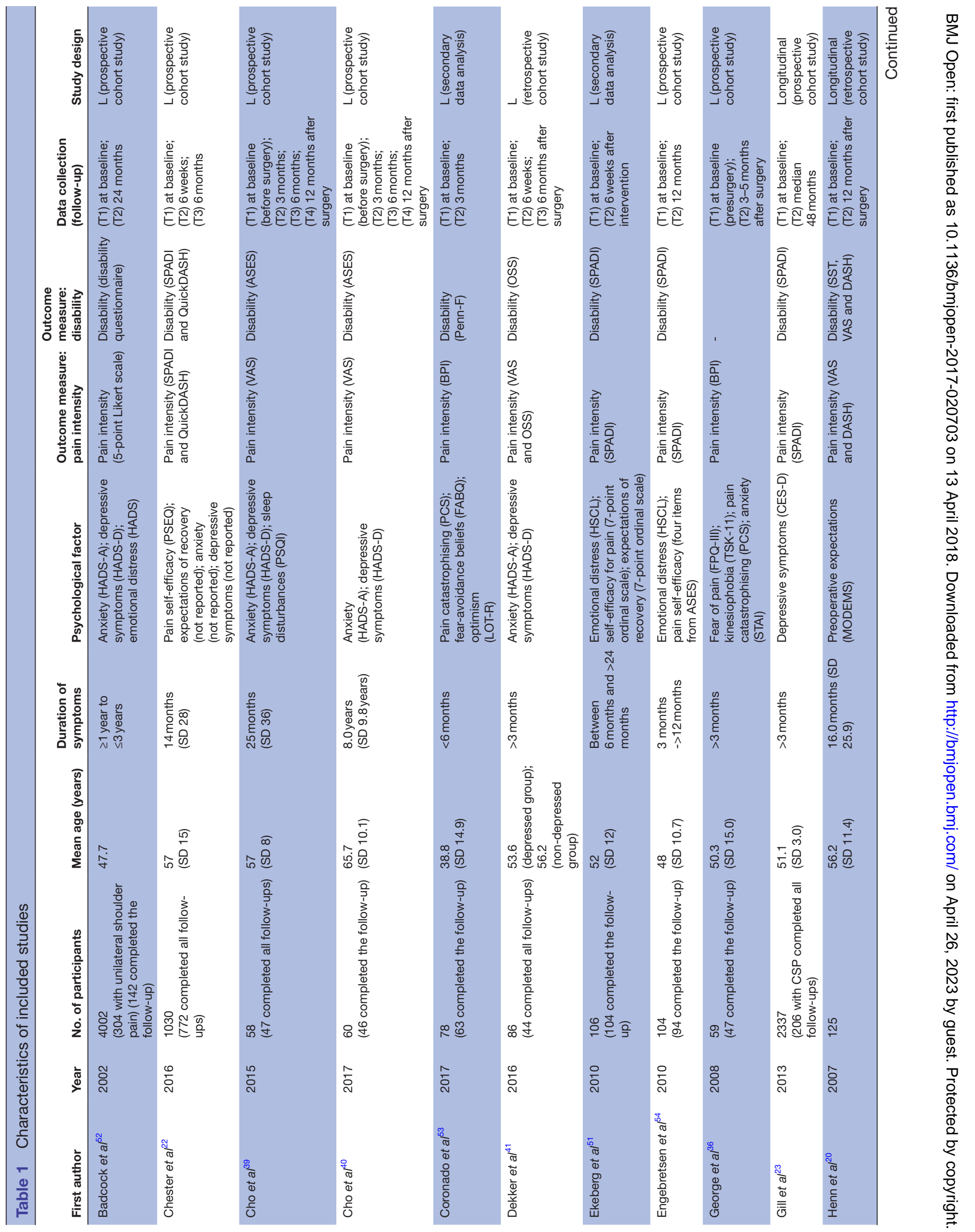




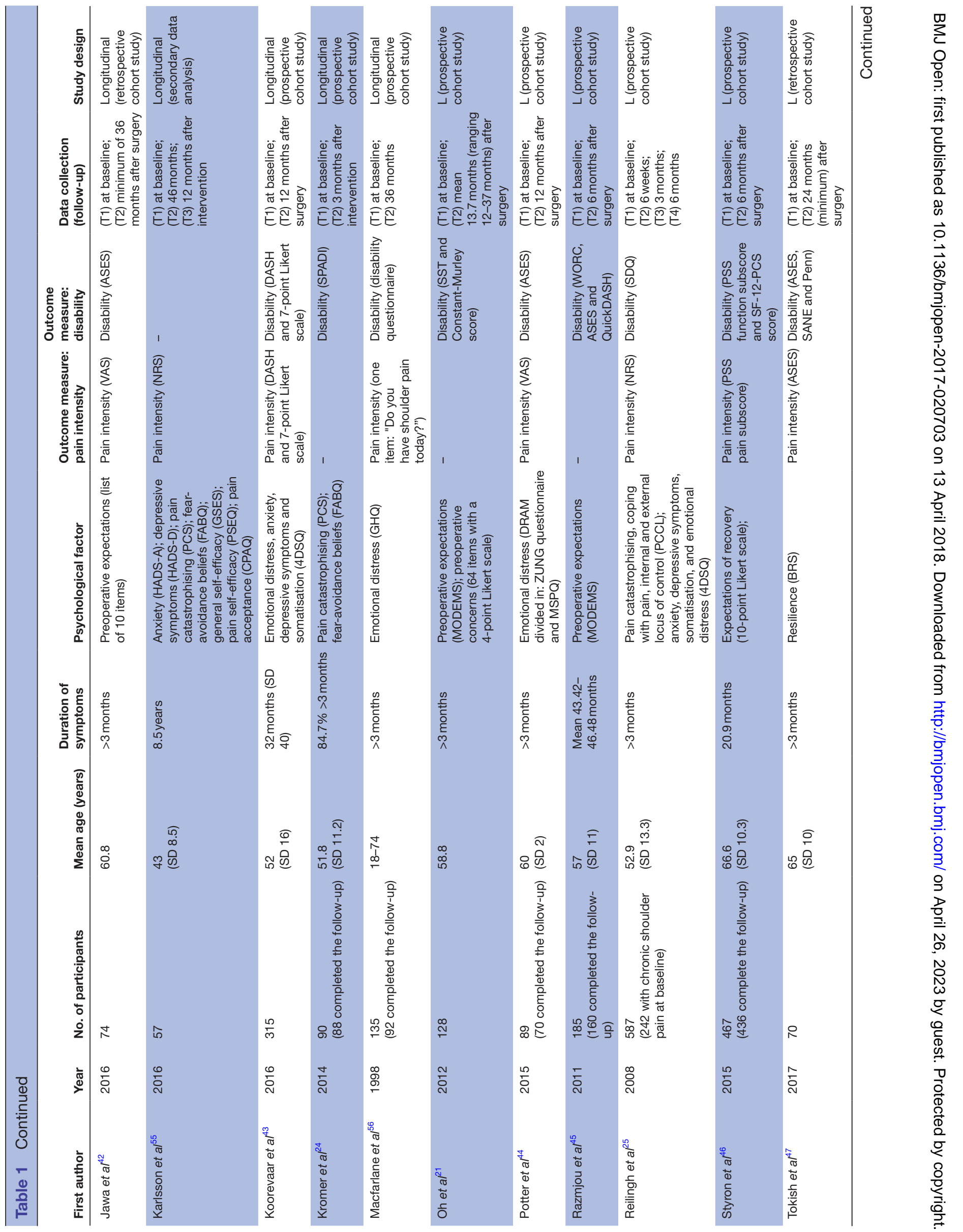




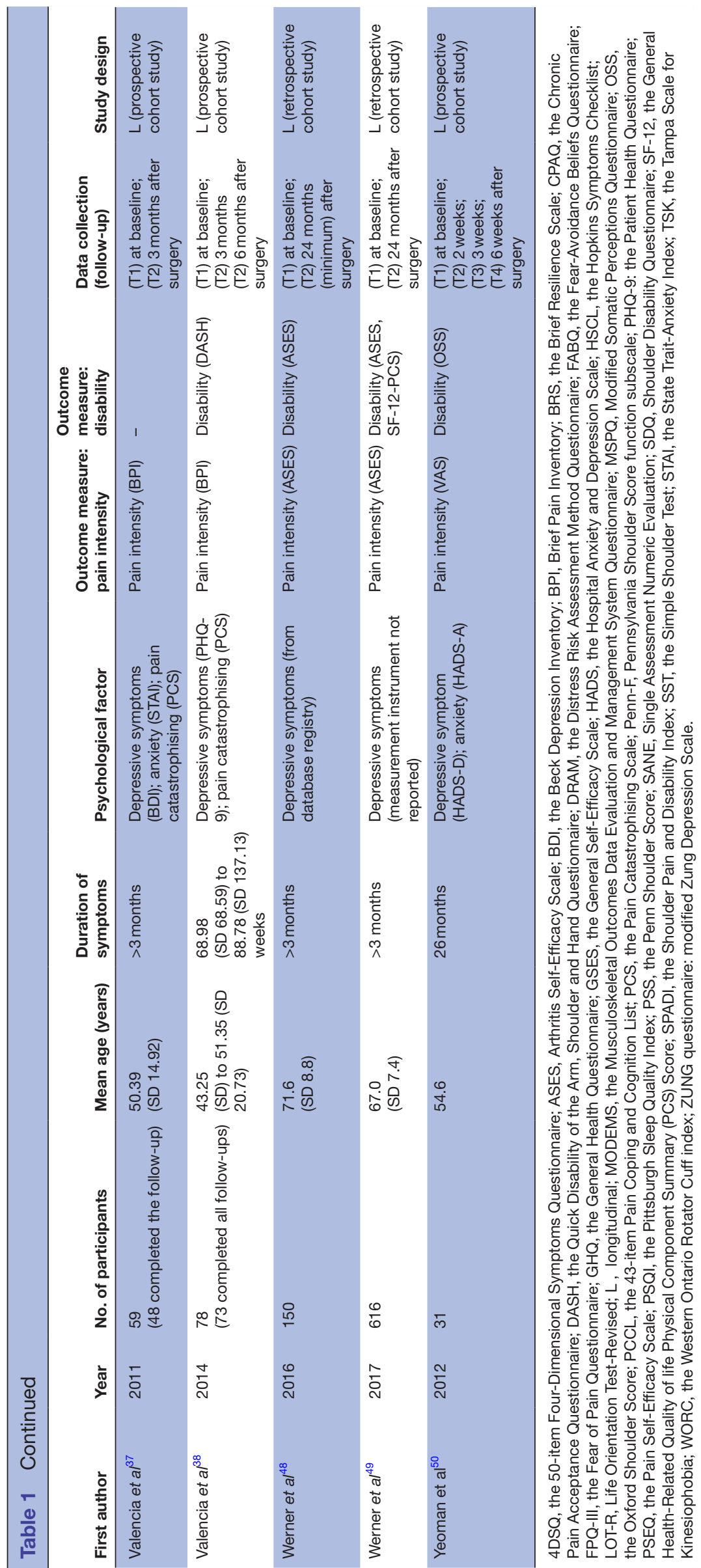


Table 2 Methodological quality of included studies (the Newcastle Ottawa Scale (NOS) adapted version)

\begin{tabular}{|c|c|c|c|c|c|c|c|c|c|}
\hline \multirow[b]{2}{*}{ First author } & \multirow[b]{2}{*}{ Year } & \multirow{2}{*}{$\begin{array}{l}\begin{array}{l}\text { Selection } \\
\text { bias }\end{array} \\
\text { A }\end{array}$} & \multicolumn{2}{|c|}{ Performance bias } & \multicolumn{2}{|c|}{ Detection bias } & \multicolumn{2}{|c|}{ Information bias } & \multirow[b]{2}{*}{ Total score } \\
\hline & & & B & C & $\mathbf{D}$ & $E$ & $\mathbf{F}$ & G & \\
\hline Badcock et $\left.a\right|^{52}$ & 2002 & 1 & 0 & 2 & 1 & 0 & 2 & 2 & $8 / 21$ \\
\hline Chester et $a l^{22}$ & 2016 & 3 & 3 & 2 & 2 & 0 & 0 & 2 & $12 / 21$ \\
\hline Cho et $\mathrm{a} \mathbf{1}^{39}$ & 2015 & 2 & 3 & 0 & 1 & 0 & 2 & 2 & $10 / 21$ \\
\hline Cho et $a l^{40}$ & 2017 & 2 & 3 & 0 & 1 & 0 & 2 & 2 & $10 / 21$ \\
\hline Coronado et $a^{53}$ & 2017 & 1 & 0 & 2 & 2 & 2 & 3 & 2 & $12 / 21$ \\
\hline Dekker et $a /^{41}$ & 2016 & 2 & 3 & 0 & 1 & 0 & 2 & 2 & $10 / 21$ \\
\hline Ekeberg et $a l^{51}$ & 2010 & 1 & 0 & 2 & 2 & 3 & 2 & 2 & $12 / 21$ \\
\hline Engebretsen et al ${ }^{54}$ & 2010 & 1 & 0 & 3 & 2 & 3 & 2 & 2 & $13 / 21$ \\
\hline George et $\left.a\right|^{36}$ & 2008 & 1 & 0 & 1 & 2 & 0 & 2 & 2 & $8 / 21$ \\
\hline Gill et $a l^{23}$ & 2013 & 1 & 0 & 3 & 2 & 3 & 2 & 2 & $13 / 21$ \\
\hline Henn III et al ${ }^{20}$ & 2007 & 1 & 0 & 2 & 2 & 3 & 2 & 2 & $12 / 21$ \\
\hline Jawa et $\left.a\right|^{42}$ & 2016 & 1 & 0 & 0 & 0 & 3 & 1 & 2 & $7 / 21$ \\
\hline Karlsson et $a^{55}$ & 2016 & 0 & 0 & 2 & 2 & 3 & 3 & 2 & $12 / 21$ \\
\hline Koorevaar et a/ $\left.\right|^{43}$ & 2016 & 1 & 0 & 2 & 2 & 3 & 3 & 2 & $13 / 21$ \\
\hline Kromer et $a^{24}$ & 2014 & 1 & 0 & 2 & 2 & 3 & 3 & 2 & $13 / 21$ \\
\hline Macfarlane et $a^{56}$ & 1998 & 1 & 0 & 2 & 0 & 0 & 2 & 2 & $7 / 21$ \\
\hline Oh et $a l^{21}$ & 2012 & 1 & 0 & 0 & 1 & 3 & 2 & 2 & $9 / 21$ \\
\hline Potter et a $\left.\right|^{44}$ & 2015 & 1 & 0 & 0 & 2 & 0 & 3 & 2 & $8 / 21$ \\
\hline Razmjou et al/ ${ }^{45}$ & 2011 & 2 & 1 & 1 & 2 & 1 & 3 & 2 & $12 / 21$ \\
\hline Reilingh et $a l^{25}$ & 2008 & 1 & 0 & 3 & 2 & 0 & 2 & 2 & $10 / 21$ \\
\hline Styron et al ${ }^{46}$ & 2015 & 1 & 0 & 2 & 1 & 1 & 1 & 2 & $8 / 21$ \\
\hline Tokish et a $\left.\right|^{47}$ & 2017 & 1 & 0 & 0 & 0 & 3 & 1 & 2 & $7 / 21$ \\
\hline Valencia et $\left.\mathrm{a}\right|^{37}$ & 2011 & 1 & 0 & 0 & 1 & 0 & 3 & 2 & $7 / 21$ \\
\hline Valencia et $\mathrm{a}^{38}$ & 2014 & 1 & 0 & 2 & 2 & 3 & 3 & 2 & $13 / 21$ \\
\hline Werner et $a l^{48}$ & 2016 & 1 & 0 & 1 & 1 & 3 & 1 & 2 & $9 / 21$ \\
\hline Werner et al ${ }^{49}$ & 2017 & 2 & 3 & 1 & 1 & 3 & 1 & 2 & $13 / 21$ \\
\hline Yeoman et al ${ }^{50}$ & 2012 & 2 & 3 & 0 & 0 & 3 & 3 & 2 & $13 / 21$ \\
\hline
\end{tabular}

A, Is the source population (cases, controls, cohorts) appropriate and representative of the population of interest? B, Is the sample size adequate and is there sufficient power to detect a meaningful difference in the outcome of interest? C, Did the study identify and adjust for any variables or confounders that may influence the outcome? D, Did the study use appropriate statistical analysis methods relative to the outcome of interest? E, Is there little missing data and did the study handle it accordingly? $\mathrm{F}$, Is the methodology of the outcome measurement explicitly stated and is it appropriate? G, Is there an objective assessment of the outcome of interest?

depressive symptoms, ${ }^{3741434849}$ anxiety, ${ }^{414350}$ pain catastrophising, ${ }^{36} 37$ emotional distress ${ }^{43}$ and somatisation ${ }^{43}$ were significantly associated with high levels of pain intensity. There was no statistical relationship between sleep disturbances, fear of pain, kinesiophobia and pain intensity in people with CSP presurgery and postsurgery.

\section{The role of psychological factors on disability in people with CSP without surgery}

The role of psychological factors on disability in people with CSP without surgery was evaluated by nine studies. ${ }^{22-25} 51-5456$ High levels of self-efficacy ${ }^{22} 54$ and expectations of recovery ${ }^{22}$ were significantly associated with low levels of disability. High levels of depressive symptoms, ${ }^{22} 2352$ anxiety, ${ }^{22} 52$ emotional distress ${ }^{52} 54$ and pain catastrophising ${ }^{53}$ were significantly associated with high levels of disability. There was no statistical relationship between coping with pain, internal and external locus of control, optimism, FA beliefs or somatisation and disability in people with CSP without surgery.

\section{The role of psychological factors on disability in people with CSP presurgery and postsurgery}

The role of psychological factors on disability in people with CSP presurgery and postsurgery was reported by 15 studies. ${ }^{20} 2138-50$ High levels of resilience ${ }^{47}$ and preoperative expectations ${ }^{20} 2146$ were significantly associated with low levels of disability. High levels of depressive symptoms, ${ }^{4143489}$ anxiety, ${ }^{41} 43$ emotional distress, ${ }^{43}$ preoperative concerns $^{21}$ and somatisation ${ }^{43}$ were significantly 
Table 3 Summary of findings and quality of evidence assessment

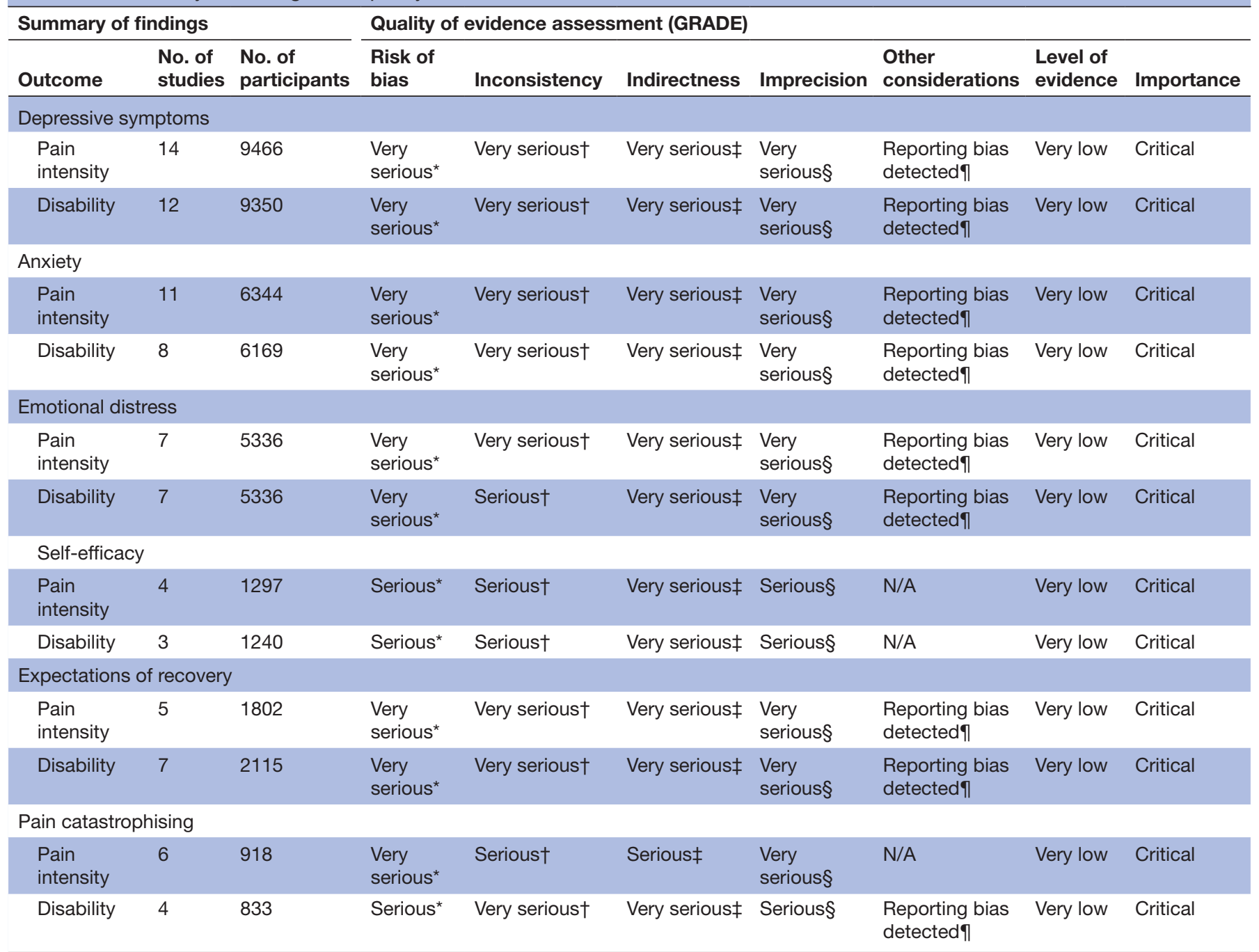

*Randomised trials (lack of allocation concealment; lack of blinding; incomplete accounting of patients and outcomes events; selective outcome reporting bias; other limitations; observational studies (failure to develop and apply appropriate eligibility criteria; flawed measurement of both exposure and outcome; failure to adequate control confounding; incomplete follow-up; non-presence of an unexposed cohort).

†Point estimates vary widely across studies; Cls show minimal or no overlap.

‡ Differences in population, differences in intervention, differences in outcome, indirect comparison.

$\S$ Optimal information size (OIS) criterion is not met and the sample size is small; OIS criterion is met but the $95 \% \mathrm{Cl}$ around an effect does not exclude 1.0 (wide $\mathrm{Cls}$ ); $95 \% \mathrm{Cl}$ is not reported.

II Outcome data not included in the predictive model.

N/A, not available.

associated with high levels of disability. There was no statistical relationship between sleep disturbances and disability in people with CSP presurgery and postsurgery.

\section{DISCUSSION}

\section{Statement of principal findings}

The objective of this systematic review was to explore the role of psychological factors in the perpetuation of symptoms (pain intensity and disability) in people with CSP, based on the analysis of longitudinal studies. Our results suggest that there is a relationship between high levels of self-efficacy, resilience and expectations of recovery with low levels of pain intensity and disability. Inversely, there is also a relationship between high levels of emotional distress, depressive symptoms, anxiety, preoperative concerns, FA beliefs, somatisation or pain catastrophising and high levels of pain intensity and disability in people with CSP. Nevertheless, the quality and the strength of evidence was very low, and the risk of bias was substantial so firm conclusions could not be drawn.

\section{Comparison with other studies}

Our findings suggest that people with CSP who present certain psychological features (eg, depressive symptoms or fear) are prone to develop greater levels of pain intensity and disability. This statement is in accordance with previous systematic reviews in chronic pain conditions ${ }^{57-60}$ 
Table 4 Summary of the statistical results about the association between psychological factors and pain intensity (longitudinal analysis)

The role of psychological factors in the perpetuation of pain intensity in people with chronic shoulder pain

The association between fear- $\quad$ Baseline fear-avoidance beliefs (physical activity subscale)-pain intensity at 3 months: $\mathrm{B}(95 \% \mathrm{Cl})=-0.01$

avoidance and pain intensity ( -0.20 to 0.19$), P=0.090^{53}$

Baseline fear-avoidance beliefs-pain intensity at baseline: $r=0.04, P=0.75$; at 4-6 months: $r=-0.33, P=0.029$; at 12 months: $r=-0.29, P=0.08^{55}$

The association between fear of Baseline fear of pain-pain intensity at $3-5$ months: standardised $B=0.08, P=0.584^{36}$

pain and pain intensity

The association between kinesiophobia and pain intensity

The association between pain catastrophising and pain intensity

Baseline kinesiophobia-pain intensity at 3 -5 months: standardised $B=-0.15, P=0.329^{36}$

Baseline pain catastrophising-pain intensity at 3 months: $B(95 \% \mathrm{Cl})=0.11(-0.11$ to 0.32$), P=0.213^{53}$

Baseline pain catastrophising-pain intensity at 3 months after surgery: standardised $B=0.34, S E=0.04$, $\mathrm{P}=0.04^{37}$

Baseline pain catastrophising-pain intensity at 3- 5 months: standardised $B=0.53, P=0.001^{36}$

Baseline pain catastrophising-pain intensity at 6 months: mean $(95 \% \mathrm{Cl})=-0.62(-1.03$ to -0.20$)$,

$\mathrm{P}=\mathbf{0 . 0 0 1 ^ { 2 5 }}$

Baseline pain catastrophising-pain intensity at 6 months after surgery: standardised $B=0.05, S E=0.03$, $\mathrm{P}=0.70^{38}$

Baseline pain catastrophising-pain intensity at baseline: $r=0.02, P=0.88$; at $4-6$ months: $r=-0.20, P=0.21$; at 12 months: $r=-0.06, P=0.73^{55}$

The association between self- $\quad$ Baseline pain self-efficacy-pain intensity at 6 weeks after intervention: $\mathrm{B}(95 \% \mathrm{Cl})=0.9(-0.2$ to 1.9$), \mathrm{P}=0.1^{51}$ efficacy and pain intensity

Baseline pain self-efficacy-pain intensity at 6 months: $\mathrm{B}(95 \% \mathrm{Cl})=-0.36(-0.50$ to -0.22$), \mathrm{P}<0.001^{22}$ Baseline pain self-efficacy-pain intensity at 12 months: $B(95 \% \mathrm{Cl})=6.0(2.0$ to 9.9$), P=0.004^{54}$

Baseline pain self-efficacy-pain intensity at baseline: $r=-0.10, P=0.45$; at $4-6$ months: $r=0.10, P=0.51$; at 12 months: $r=-0.20, P=0.23^{55}$

Baseline general self-efficacy-pain intensity at baseline: $r=0.12, P=0.37$; at 4-6 months: $r=0.21, P=0.18$; at 12 months: $r=0.19, P=0.27^{55}$

The association between expectations of recovery and pain intensity

Baseline expectations of recovery-pain intensity at 6 weeks after intervention: $\mathrm{B}(95 \% \mathrm{Cl})=2.3(-8.0$ to 12.6$)$, $\mathrm{P}=0.66^{51}$

Baseline expectations of recovery-pain intensity at 6 months: much improved: $\mathrm{B}(95 \% \mathrm{Cl})=-5.21(-1.80$ to 8.61), $P=0.003$; slightly improved: $B(95 \% \mathrm{Cl})=-12.43(-8.20$ to -16.67$), P<0.001$; no changes/worse: $\mathrm{B}(95 \% \mathrm{Cl})=-0.94(-8.53$ to 6.66$), \mathrm{P}=0.809^{22}$

Baseline expectations of recovery-pain intensity at 6 months (PSS pain subscore): mean $(95 \% \mathrm{Cl})=1.99$ (0.17 to 3.82$), P=0.033^{46}$

Preoperative expectations-pain intensity at 12 months: VAS $B=9.91, P=0.005$; DASH: $B=11.93, P<0.001^{20}$ Association between preoperative expectations and pain intensity at a minimum of 3 years was not reported ${ }^{42}$

The association between optimism and pain intensity

The association between internal and external locus of control and pain intensity

The association between pain acceptance and pain intensity
Baseline optimism (in the model with pain catastrophising)-pain intensity at 3 months: $\mathrm{B}(95 \% \mathrm{Cl})=-0.01$ $(-0.20 \text { to } 0.19)^{53}$

Baseline optimism (in the model with fear-avoidance beliefs)-pain intensity at 3 months: $\mathrm{B}(95 \% \mathrm{Cl})=-0.04$ $(-0.22 \text { to } 0.15)^{53}$

Baseline external locus of control-pain intensity at 6 months: $3-4$ : mean $(95 \% \mathrm{Cl})=-0.79(-1.60$ to 0.02$)$, $\mathrm{P}=0.06$; $>$ : mean $(95 \% \mathrm{Cl})=0.21$ ( -0.92 to 1.35$), \mathrm{P}=0.71^{25}$

Baseline pain acceptance-pain intensity at baseline: $r=-0.14, P=0.32$; at $4-6$ months: $r=0.14, P=0.40$; at 12 months: $r=-0.00, P=0.99^{55}$

The association between coping Association between coping and pain intensity at 6 months was not reported ${ }^{25}$ and pain intensity

\section{The association between} resilience and pain intensity

The association between sleep disturbances and pain intensity

The association between somatisation and pain intensity

\section{Postoperative resilience-pain intensity (ASES): $r=0.41-0.44, \mathrm{P}<0.004^{47}$}

Baseline sleep disturbances-pain intensity at 12 months after surgery: coefficient $(95 \% \mathrm{Cl})=0.040(-0.082$ to $0.163), P=0.664^{39}$

Baseline somatisation-pain intensity at 6 months: mean $(95 \% \mathrm{Cl})=-0.16(-1.01$ to 0.68$), \mathrm{P}=0.71^{25}$

Baseline somatisation-pain intensity (DASH) at 12 months: coefficient $(95 \% \mathrm{Cl})=-3.00(-10.53$ to 4.52$)$, $\mathrm{P}=0.43$; pain intensity at 12 months (Likert scale): coefficient $(95 \% \mathrm{Cl})=-0.12(-0.62$ to 0.37$), \mathrm{P}=0.63^{43}$ Somatisation at 12 months-pain intensity (DASH) at 12 months: coefficient $(95 \% \mathrm{Cl})=-\mathbf{1 4 . 3 7}(-\mathbf{2 1 . 2 3}$ to -7.51), $\mathrm{P}<0.001$; pain intensity at 12 months (Likert scale): coefficient $(95 \% \mathrm{Cl})=-0.37(-0.82$ to -0.83$)$, $\mathrm{P}=0.11^{43}$ 
Table 4 Continued

The role of psychological factors in the perpetuation of pain intensity in people with chronic shoulder pain

The association between emotional distress and pain intensity

Emotional distress-pain intensity at 6 weeks after intervention: $\mathrm{B}(95 \% \mathrm{Cl})=7.4(-3.0$ to 17.8$), \mathrm{P}=0.16^{51}$

Baseline emotional distress-pain intensity at 12 months: $\mathrm{B}(95 \% \mathrm{Cl})=10.3(-1$ to 21.6$), \mathrm{P}=\mathbf{0 . 0 7 3 ^ { 5 4 }}$

Baseline emotional distress-pain intensity (DASH) at 12 months: coefficient $(95 \% \mathrm{Cl})=0.30$ ( -6.09 to 6.7), $\mathrm{P}=0.93$; pain intensity at 12 months (Likert scale): coefficient $(95 \% \mathrm{Cl})=0.31(-0.12$ to 0.74$), \mathrm{P}=0.16^{43}$ Emotional distress at 12 months-pain intensity (DASH) at 12 months: coefficient $(\mathbf{9 5} \% \mathbf{C l})=\mathbf{- 2 0 . 6 3}(\mathbf{- 2 7 . 2 5}$ to -14.00$), P<0.001$; pain intensity at 12 months (Likert scale): coefficient $(95 \% \mathrm{Cl})=-0.95(-1.39$ to -0.51$)$, $P<0.001^{43}$

Baseline emotional distress (ZUNG questionnaire)-pain intensity at 12 months: $B=-0.18, P=0.084$

Baseline emotional distress (MSPQ)-pain intensity at 12 months: $B=-0.10, P=0.658^{44}$

Baseline emotional distress-pain intensity at 3 years: GHQ score $0-1$ : OR (95\% IC) $=1.0$; GHQ score 2-4: OR $(95 \% \mathrm{Cl})=0.8$ (0.3 to 2.7$) ; \mathrm{GHQ}$ score $\geq 5$ : OR $(95 \% \mathrm{Cl})=2.6(0.8 \text { to } 7.7)^{56}$

Changes in emotional distress and changes in pain intensity at 24 months were not reported ${ }^{52}$ Association between emotional distress and pain intensity was not reported ${ }^{25}$

The association between depressive symptoms and pain intensity

\section{Baseline depressive symptoms-pain intensity 2 weeks postsurgery: $r=0.463$; 3 weeks: $r=0.261$; 6 weeks;} $r=0.191^{50}$

Baseline depressive symptoms-pain intensity at 3 months after surgery: standardised $B=0.33, S E=0.06$, $\mathbf{P}=0.04^{37}$

Baseline depressive symptoms-pain intensity at 6 months after surgery: standardised $B=0.18, S E=0.05$, $\mathrm{P}=0.15^{38}$

Baseline depressive symptoms-pain intensity at baseline $(r=0.309, P<0.05) ; 6$ weeks $(r=0.376, P<0.01)$; 6 months after surgery $(r=0.508, P<0.01)^{41}$

Baseline depressive symptoms-pain intensity (OSS) at baseline $(r=-0.319, P<0.01) ; 6$ weeks

$(r=-0.490, P<0.01) ; 6$ months after surgery $(r=-0.626, P<0.01)^{41}$

Baseline depressive symptoms-pain intensity at 48 months (median): no depression: $O R=1$; depressive symptoms: OR $(95 \% \mathrm{Cl})=1.96(1.07$ to 3.58$), \mathrm{P}=0.029^{23}$

Baseline depressive symptoms-pain intensity at 12 months after surgery: coefficient $(95 \% \mathrm{Cl})=-0.073(-0.298$ to 0.152$), P=0.515^{39}$

Baseline depressive symptoms-pain intensity at 12 months after surgery: coefficient $(95 \% \mathrm{Cl})=-0.016(-0.276$ to 0.244$), P=0.899^{40}$

Baseline depressive symptoms-pain intensity at baseline: $r=0.14, P=0.29$; at 4-6 months: $r=-0.19, P=0.22$; at 12 months: $r=-0.11, P=0.95^{55}$

Baseline depressive symptoms-pain intensity (DASH) at 12 months: coefficient $(95 \% \mathrm{Cl})=-4.68(-14.72$ to -5.36), $\mathrm{P}=0.36$; pain intensity at 12 months (Likert scale): coefficient $(95 \% \mathrm{Cl})=0.09(-0.56$ to 0.74$), \mathrm{P}=0.78^{43}$ Depressive symptoms at 12 months-pain intensity (DASH) at 12 months: coefficient $(95 \% \mathrm{Cl})=-16.59$ ( -23.86 to -9.32$), P<0.001$; pain intensity at 12 months (Likert scale): coefficient $(95 \% \mathrm{Cl})=-\mathbf{0 . 7 9}(-\mathbf{1 . 2 6}$ to $-0.32), P=0.001^{43}$

Baseline depressive symptoms-pain intensity at a minimum of 24 months: OR $(95 \% \mathrm{Cl})=11.2(2.0$ to 61.3), $\mathrm{P}=0.005^{48}$

Baseline depressive symptoms-pain intensity (ASES) at 24 months: $P=0.018^{49}$

Changes in depressive symptoms and changes in pain intensity at 24 months were not reported ${ }^{52}$ Association between depressive symptoms and pain intensity was not reported ${ }^{25}$

The association between anxiety and pain intensity
Baseline anxiety-pain intensity 2 weeks postsurgery: $r=0.026, P<0.05$; 3 weeks: $r=0.364 ; 6$ weeks: $r=0.301^{50}$ Baseline anxiety-pain intensity at 3 month after surgery: standardised $B=-0.22, S E=0.04, P=0.26^{37}$

Baseline anxiety-pain intensity at $3-5$ months: standardised $B=0.07, P=0.646^{36}$

Baseline anxiety-pain intensity at baseline $(r=0.309, P<0.05)$; 6 weeks $(r=0.376, P<0.01)$; 6 months after surgery $(r=0.508, P<0.01)^{41}$

Baseline anxiety-pain intensity (OSS) at baseline $(r=-0.319, P<0.01) ; 6$ weeks $(r=-0.490, P<0.01)$; 6 months after surgery $(r=-0.626, P<0.01)^{41}$

Baseline anxiety-pain intensity at 12 months after surgery: coefficient $(95 \% \mathrm{Cl})=0.115(-0.053$ to 0.283$)$, $\mathrm{P}=0.174^{39}$

Baseline anxiety-pain intensity at 12 months after surgery: coefficient $(95 \% \mathrm{Cl})=-0.010(-0.363$ to 0.142$)$, $\mathrm{P}=0.382^{40}$

Baseline anxiety-pain intensity at baseline: $r=0.16, P=0.26$; at $4-6$ months: $r=-0.18, P=0.22$; at 12 months: $r=-0.26, P=0.13^{55}$

Baseline anxiety-pain intensity (DASH) at 12 months: coefficient $(95 \% \mathrm{Cl})=-6.25(-13.84$ to 1.30$), \mathrm{P}=0.10$; pain intensity at 12 months (Likert scale): coefficient $(95 \% \mathrm{Cl})=-0.27(-0.75$ to 0.21$), P=0.27^{43}$

Anxiety at 12 months-pain intensity (DASH) at 12 months: coefficient $(95 \% \mathrm{Cl})=\mathbf{- 1 1 . 6 2}(\mathbf{- 1 9 . 1 5}$ to -4.10$)$, $\mathbf{P}=\mathbf{0 . 0 0 3}$; pain intensity at 12 months (Likert scale): coefficient $(95 \% \mathrm{Cl})=-0.46(-0.94$ to 0.19$), P=0.06^{43}$ Changes in anxiety and changes in pain intensity at 24 months were not reported ${ }^{52}$

Association between anxiety and pain intensity was not reported ${ }^{25}$

*Significant results are shown in bold.

ASES, Arthritis Self-Efficacy Scale; B, beta-coefficient; DASH, the Quick Disability of the Arm, Shoulder and Hand Questionnaire; GHQ, the General Health Questionnaire; MSPQ, Modified Somatic Perceptions Questionnaire; OSS, the Oxford Shoulder Score; PSS, the Penn Shoulder Score; r, Pearson's coefficient of correlation; VAS, Visual Analogue Scale; ZUNG questionnaire: modified Zung Depression Scale. 
Table 5 Summary of the statistical results for the association between psychological factors and disability (Iongitudinal analysis)

The role of psychological factors in the perpetuation of disability in people with chronic shoulder pain

The association between fear- Baseline fear-avoidance (physical activity subscale)-disability (function) at $3 \mathrm{months:} \mathrm{B}(95 \% \mathrm{Cl})=-0.13(-0.31$ avoidance and disability to 0.05$), P=0.092^{53}$

Baseline fear-avoidance beliefs-disability at 3 months: $B(95 \% \mathrm{Cl})=-0.102(-1.14$ to -0.36$), P=0.305, V I F=1.51^{24}$

The association between pain catastrophising and disability

Baseline pain catastrophising-disability (function) at 3 months: $\mathrm{B}(95 \% \mathrm{Cl})=-0.19(-0.37$ to -0.01$)$, $P<0.05^{53}$

Baseline pain catastrophising-disability at 3 months: $B(95 \% \mathrm{Cl})=0.083(-0.23$ to 0.59$), P=0.381, \mathrm{VIF}=1.40^{24}$ Baseline pain catastrophising-disability at 6 months after surgery: standardised $B=0.23, S E=0.24, P=0.11^{38}$ Association between baseline pain catastrophising-disability at 6 months was not reported ${ }^{25}$

The association between self- Baseline pain self-efficacy-disability at 6 weeks after intervention: $\mathrm{B}(95 \% \mathrm{Cl})=0.9(-0.2$ to 1.9$)$, $\mathrm{P}=0.1^{51}$ efficacy and disability

Baseline pain self-efficacy-disability at 6 months follow-up: $\mathrm{B}(95 \% \mathrm{Cl})=-0.36(-0.50$ to -0.22$), \mathrm{P}<0.001$ (statistical data of QuickDASH not reported) ${ }^{22}$

Baseline pain self-efficacy-disability at 12 months: $B(95 \% \mathrm{Cl})=6.0(2.0$ to 9.9$), P=0.004^{54}$

The association between expectations of recovery and disability

Baseline expectations of recovery-disability at 6 weeks after intervention: $\mathrm{B}(95 \% \mathrm{Cl})=2.3(-8.0$ to 12.6$)$, $\mathrm{P}=0.66^{51}$

Baseline expectations of recovery-disability at 6 months: much improved: $\mathrm{B}(95 \% \mathrm{Cl})=-5.21(-1.80$ to 8.61), $\mathrm{P}=0.003$; slightly improved: $\mathrm{B}(95 \% \mathrm{Cl})=-12.43$ (-8.20 to -16.67$), \mathrm{P}<0.001$; no changes/worse: $\mathrm{B}(95 \% \mathrm{Cl})=-0.94(-8.53$ to 6.66$), \mathrm{P}=0.809$ (statistical data of QuickDASH not reported) ${ }^{22}$

Preoperative expectations-disability at 6 months: $F$ value $=1.89 \mathrm{df}\left(R^{2}\right)=3, P=0.1349^{45}$

Baseline expectations of recovery-disability at 6 months (PSS-function subscore): mean $(95 \% \mathrm{Cl})=\mathbf{2 . 6 5}$

(0.14 to 5.16), $\mathrm{P}=\mathbf{0 . 0 3 9}$; (SF-12-PCS score): mean ( $95 \% \mathrm{Cl})=-0.06$ ( -0.78 to 0.65$), \mathrm{P}=0.858^{46}$

Preoperative expectations-disability at 12 months: VAS $B=8.30, P=0.023$; DASH: $B=11.93, P<0.001$; SST:

$B=15.34, P<0.001^{20}$

High expectations at follow-up-disability Constant Murley at baseline: OR $(95 \% \mathrm{Cl})=0.868(0.82$ to $0.91), P<0.001, R^{2}=-0.142 ;$ SST: $P=0.007^{2}$

Association preoperative expectations-disability at a minimum of 3 years was not reported ${ }^{42}$

The association between optimism and disability

\section{Baseline optimism (in the model with pain catastrophising)-disability (function) at 3 months: $\mathrm{B}(95 \% \mathrm{Cl})=0.05$} $(-0.12 \text { to } 0.22)^{53}$

Baseline optimism (in the model with fear-avoidance beliefs)-disability (function) at 3 months: $\mathrm{B}(95 \% \mathrm{Cl})=0.10$ $(-0.06 \text { to } 0.26)^{53}$

The association between internal and external locus of control and disability

\section{The association between coping and disability}

The association between resilience and disability

$$
\text { Association between baseline locus of control-disability at } 6 \text { months was not reported }{ }^{25}
$$

Association between coping and disability at 6 months was not reported ${ }^{25}$

$$
\text { Postoperative resilience-disability (ASES and Penn): } r=0.41-0.44, P<0.004^{47}
$$
$\begin{array}{ll}\text { The association between sleep } & \text { Baseline sleep disturbances-disability at } 12 \text { months after surgery: coefficient }(95 \% \mathrm{Cl})=0.386(--1.330 \text { to } \\ \text { disturbances and disability } & 0.558), \mathrm{P}=0.415^{39}\end{array}$

The association between preoperative concerns and disability

The association between somatisation and disability

The association between emotional distress and disability
Preoperative concerns-disability Constant Murley: $P=0.361$; SST: $P=\mathbf{0 . 0 1 8 ^ { 2 1 }}$

Baseline somatisation-disability (DASH) at 12 months: coefficient $(95 \% \mathrm{Cl})=-3.00(-10.53$ to 4.52$), \mathrm{P}=0.43$; disability at 12 months (Likert scale): coefficient $(95 \% \mathrm{CI})=-0.12(-0.68$ to 0.45$), P=0.69^{43}$

Somatisation at 12 months-disability (DASH) at 12 months: coefficient $(95 \% \mathrm{Cl})=-14.37(-21.23$ to -7.51$)$, $\mathrm{P}<0.001$; disability at 12 months (Likert scale): coefficient $(95 \% \mathrm{Cl})=-0.62(-1.13$ to -0.10$), P=0.02^{43}$ Association between baseline somatisation-disability at 6 months was not reported ${ }^{25}$

Emotional distress-disability at 6 weeks after intervention: $\mathrm{B}(95 \% \mathrm{Cl})=7.4(-3.0$ to 17.8$), \mathrm{P}=0.16^{51}$ Baseline emotional distress-disability at 12 months: $B(95 \% \mathrm{Cl})=10.3(-1$ to 21.6$), P=0.073^{54}$

Baseline emotional distress-disability (DASH) at 12 months: coefficient $(95 \% \mathrm{Cl})=0.30$ (-6.09 to 6.7), $\mathrm{P}=0.93$; disability at 12 months (Likert scale): coefficient $(95 \% \mathrm{Cl})=0.19(-0.31$ to 0.69$), \mathrm{P}=0.45^{43}$

Emotional distress at 12 months-disability (DASH) at 12 months: coefficient $(95 \% \mathrm{Cl})=-\mathbf{2 0 . 6 3}(-\mathbf{2 7 . 2 5}$ to -14.00$), \mathrm{P}<0.001$; disability at 12 months (Likert scale): coefficient $(95 \% \mathrm{Cl})=-0.98(-1.49$ to -0.47$)$, $P<0.001^{43}$

Baseline ZUNG questionnaire-disability at 12 months: $B=0.44, P=0.262$; baseline MSPQ-disability at 12 months: $B=-0.40, P=0.645^{44}$

Changes emotional distress-changes disability at 24 months: $r=0.341, P=0.002^{52}$

Association between baseline emotional distress-disability at 6 months was not reported ${ }^{25}$

Association between baseline emotional distress-disability at 3 years was not reported ${ }^{56}$ 
Table 5 Continued

The role of psychological factors in the perpetuation of disability in people with chronic shoulder pain

The association between depressive symptoms and disability
Baseline depressive symptoms-disability 2 weeks postsurgery: $r=0.206$; 3 weeks: $r=0.947 ; 6$ weeks: $r=0.405^{50}$ Baseline depressive symptoms-disability at 6 months: moderate: $\mathrm{B}(95 \% \mathrm{Cl})=2.19(-0.99$ to 5.37$), \mathrm{P}=0.177$; extreme: $\mathrm{B}(95 \% \mathrm{Cl})=12.02$ (1.49 to 22.56$), \mathrm{P}=0.025$ (statistical data of QuickDASH not reported) ${ }^{22}$ Baseline depressive symptoms-disability (OSS) at baseline $(r=-0.319, P<0.01) ; 6$ weeks $(r=-0.490, P<0.01) ; 6$ months after surgery $(r=-0.626, P<0.01)^{41}$

Baseline depressive symptoms-disability at 6 months after surgery: standardised $B=0.16, S E=0.39, P=0.24^{38}$ Baseline depressive symptoms-disability at 12 months after surgery: coefficient $(95 \% \mathrm{Cl})=0.235(-1.492$ to 1.963), $P=0.785^{39}$

Baseline depressive symptoms-disability at 12 months after surgery: coefficient $(95 \% \mathrm{Cl})=0.140(-2.030$ to 2.309), $\mathrm{P}=0.897^{40}$

Baseline depressive symptoms-disability (DASH) at 12 months: coefficient $(95 \% \mathrm{Cl})=-4.68(-14.72$ to -5.36$)$, $\mathrm{P}=0.36$; disability at 12 months (Likert scale): coefficient $(95 \% \mathrm{Cl})=0.07(-0.68$ to 0.82$), \mathrm{P}=0.85^{43}$

Depressive symptoms at 12 months-disability (DASH) at 12 months: coefficient $(95 \% \mathrm{Cl})=-16.59(-23.86$ to -9.32), $\mathrm{P}<0.001$; disability at 12 months (Likert scale): coefficient $(95 \% \mathrm{CI})=-0.93(-1.47$ to -0.38$), P=0.001^{43}$ Baseline depressive symptoms-disability at a minimum of 24 months: OR $(95 \% \mathrm{Cl})=11.2(2.0$ to 61.3$)$, $\mathrm{P}=0.005^{48}$

Baseline depressive symptoms-disability (ASES) at 24 months: $P=0.018^{49}$

Baseline depressive symptoms-SF-12-PCS at 24 months: $P=0.006^{49}$

Changes depressive symptoms-changes disability at 24 months: $r=0.372, P=0.001^{52}$

Baseline depressive symptoms-disability at 4 years (median): no depression: $O R=1$; depressive symptoms: OR $(95 \% \mathrm{Cl})=1.96(1.07$ to 3.58$), \mathrm{P}=0.029^{23}$

Association between baseline depressive symptoms-disability at 6 months was not reported ${ }^{25}$

The association between anxiety and disability

Baseline anxiety-disability 2 weeks postsurgery: $r=0.087 ; 3$ weeks: $r=0.817$; 6 weeks: $r=0.341^{50}$

Baseline anxiety-disability at 6 months: moderate: $\mathrm{B}(95 \% \mathrm{Cl})=2.19(-0.99$ to 5.37$), \mathrm{P}=0.177$; extreme:

$B(95 \% \mathrm{Cl})=12.02(1.49$ to 22.56$), \mathrm{P}=0.025$

(statistical data of QuickDASH not reported) $)^{22}$

Baseline anxiety-disability (OSS) at baseline $(r=-0.319, P<0.01) ; 6$ weeks $(r=-0.490, P<0.01) ; 6$ months after surgery $(r=-0.626, P<0.01)^{41}$

Baseline anxiety-disability at 12 months after surgery: coefficient $(95 \% \mathrm{Cl})=-0.624(-1.913$ to 0.665$)$, $\mathrm{P}=0.335^{39}$

Baseline anxiety-disability at 12 months after surgery: coefficient $(95 \% \mathrm{Cl})=0.787(-1.318$ to 2.893$), P=0.454^{40}$ Baseline anxiety-disability (DASH) at 12 months: coefficient $(95 \% \mathrm{Cl})=-6.25(-13.84$ to 1.30$), \mathrm{P}=0.10$; disability at 12 months (Likert scale): coefficient $(95 \% \mathrm{Cl})=-0.33(-0.89$ to 0.23$), \mathrm{P}=0.24^{43}$

Anxiety at 12 months-disability (DASH) at 12 months: coefficient $(95 \% \mathrm{Cl})=-\mathbf{1 1 . 6 2}(\mathbf{- 1 9 . 1 5}$ to $-\mathbf{4 . 1 0})$,

$\mathrm{P}=0.003$; disability at 12 months (Likert scale): coefficient $(95 \% \mathrm{Cl})=-0.47(-1.03$ to -0.08$), P=0.10^{43}$

Changes anxiety-changes disability at 24 months: $r=0.265, P=0.017^{52}$

Association between baseline anxiety-disability at 6 months was not reported ${ }^{25}$

*Significant results are shown in bold.

B, beta-coefficient; DASH, the Quick Disability of the Arm, Shoulder and Hand Questionnaire; F, Fstatistics; PSS, the Penn Shoulder Score; r, Pearson's coefficient of correlation; $R^{2}$, coefficient of determination; SF-12, the General Health-Related Quality of life Physical Component Summary (PCS) Score; SST, the Simple Shoulder Test; VAS, Visual Analogue Scale; VIF, variance inflation factor.

and with the FA model of pain. ${ }^{14-16}$ In brief, this model argues that people with high levels of pain catastrophising or fear, perceive their pain as a threat. Interestingly, they develop avoidance behaviours in order to prevent this real or potential injury or re-injury. Defensive escape behaviours are an adaptive response when a real or potential aversive outcome is imminent. ${ }^{61}$ However, in chronic stages, these behaviours become maladaptive, which facilitates the physical inactivity of the affected area. ${ }^{15}$ In the case of people with CSP, the disuse of the affected shoulder could diminish the ability to carry out daily life activities such as driving a vehicle, holding an object and/or or sleeping properly. A vicious cycle starts to emerge, as people with CSP might not understand how to confront their pain in different situations, and why that pain is not disappearing, even after a conservative treatment or surgical procedure. This could increase the levels of depressive symptoms, anxiety and fear, which affects the way in which the individuals perceive their pain experience, and therefore may cause more pain intensity and disability. ${ }^{15}$

Inversely, our results also suggest that people with CSP who present high levels of self-efficacy and expectations of recovery, may be able to have both better control and management of their lives. ${ }^{62}$ People with CSP may be able to confront any daily situation that minimises the potential impact of the negative psychological factors mentioned above (eg, pain catastrophising). Several systematic reviews have explored the role of self-efficacy ${ }^{6263}$ and expectations of recovery ${ }^{64}$ in patients with chronic pain. Jackson et $a t^{62}$ concluded after analysing 86 studies that self-efficacy has a significant reverse association with disability, emotional distress and pain severity. Martinez-Calderon $e t a l^{63}$ reported that high levels of self-efficacy predict greater physical functioning, physical activity participation, health status and low pain intensity, disability and depressive symptoms, in chronic musculoskeletal pain. Ellis et $a l^{64}$ found a positive 
short-term association between expectations of recovery and patient's satisfaction and functional outcomes, after lumbar spine surgery. Therefore, the findings reported by our study and previous reviews ${ }^{57-606264}$ seem to support the potential role of psychological factors, favouring the perpetuation of pain intensity and disability in people with CSP, and minimising these symptoms based on their potential protective factors, for example, self-efficacy or expectations of recovery.

However, despite these promising findings, a lack of uniformity in terms of significance still exists, and our conclusions should be taken with caution. Several reasons could explain this issue. First, contrary to the FA model of pain, pain intensity has been considered as a robust and unique predictor of disability, ${ }^{6566}$ with it itself being a threatening experience that drives escape and avoidance. ${ }^{67}$ Second, the number and duration of episodes, fluctuations of symptoms, healthcare use and the biopsychosocial profile of every individual with CSP, can vary considerably. Therefore, these individual differences in the development and the course of symptoms in people with CSP should be kept in mind when interpreting the contribution of each psychological factor during different stages of pain in order to convey a more comprehensive picture of this entity.

\section{Strengths and weaknesses of the study}

The strengths of this systematic review included the use of a prespecified protocol registered on PROSPERO, the PRISMA checklist, the GRADE approach to evaluate the overall quality and strength of the evidence, and the adapted NOS to determine the risk of bias in each study. There are several limitations that should be mentioned, as follows: (i) despite this review having been designed to be comprehensive with a robust search strategy that used a long variety of MeSH terms, as well as a manual search and grey literature, it is possible that some studies were not identified; (ii) some psychological factors are quite broad in definition and may increase the risk of finding conflicting evidence in their association with outcomes; (iii) risk of bias was reported in most of the included studies (table 2). For instance, reporting bias was revealed in some included studies and this could limit the findings of the present systematic review; (iv) a meta-analysis was not carried out because the heterogeneity of the included studies was too high, consequently the results of the present study are not robust, and conclusions should be interpreted with caution; (v) the causality and the impact of psychological factors in pain intensity and disability in this population cannot be determined due to the observational nature of the included studies (cohort studies without a non-exposed cohort), as well as the very low evidence of the obtained findings, and hence, firm conclusions could not be drawn; (vi) some shoulder presentations (eg, traumatic) were not considered as criteria in our search strategy, giving rise to the possibility of missing potential articles; (vii) despite the post-traumatic stress disorder profile being considered a relevant factor in other musculoskeletal conditions, for example, whiplash, this profile was not considered as a criteria in our search strategy; (viii) understanding about how psychological factors influence the transition from acute to CSP could be very important in establishing preventive strategies; however, this review did not include longitudinal studies examining the transition from acute to CSP.

\section{Implications for clinical practice}

Many psychological factors included in this study are considered a barrier to the adherence to treatment in different pain conditions. ${ }^{68} 69$ However, psychological factors such as self-efficacy or pain catastrophising are considered modifiable factors that may facilitate pain relief and function recovery. ${ }^{70}$ Therefore, clinicians and surgeons should be encouraged to identify these factors, through an assessment of the psychological profile of each individual with CSP, in the first consultation. Obtaining this information may be relevant to assist health providers in clinical decision-making with the aim of targeting which interventions (eg, pharmacological and/or behavioural) could be appropriate in enhancing positive (eg, self-efficacy) or reducing negative (eg, pain catastrophising) psychological factors.

\section{Implications for further research}

Despite the promising results found in this systematic review, a clear gap seems to exist in the literature which should be filled. This is based mainly on the flaws observed in the majority of the included studies in this review. Hence, some recommendations to guide future research are: (i) further studies prospectively analysing the role of psychological factors on pain intensity and disability in people with CSP including a non-exposed cohort; (ii) studies examining the role of psychological factors on CSP standardising metrics to assess psychological factors and outcome measures; (iii) studies establishing specific definitions for each psychological factor construct (eg, a clear distinction between fear of pain, FA beliefs or kinesiophobia); (iv) studies targeting modifiable psychological factors through biopsychosocial approaches; (v) studies exploring the role of psychological factors on treatment adherence in people with CSP; (vi) as CSP is a complex entity, a long list of factors (biological, biomechanical, occupational, contextual, environmental) apart from the psychological ones should be kept in mind prior to developing observational and experimental studies. Cluster analysis and mediation analysis are examples that may help to determine the importance of each factor.

\section{CONCLUSIONS}

This systematic review provides information about the role of psychological factors on pain intensity and disability in people with CSP. The available evidence suggests that there is a relationship between high levels of self-efficacy, resilience or expectations of recovery and low levels of pain intensity and disability. Inversely, there is also a 
relationship between high levels of emotional distress, depressive symptoms, anxiety, preoperative concerns, FA beliefs, somatisation or pain catastrophising and high levels of pain intensity and disability in people with CSP. Nevertheless, due to the very low quality of the evidence, firm conclusions cannot be drawn, and further research is needed.

Acknowledgements The authors would like to express their gratitude to the University of Malaga for their support through the predoctoral grant obtained by JM-C.

Contributors JM-C and AL-S contributed to the conception of this study. JM-C, AL-S, JMM-A were involved in the selection of the included studies. JM-C, AL-S, JMM-A, GG-N, MM and FS were involved in the writing and in the review of the manuscript.

Funding The University of Malaga through a predoctoral grant supports JM-C, a $\mathrm{PhD}$ student at the University.

Competing interests All authors state that the founders had no role in the study and they have no conflicts of interest to declare. All authors have made a substantial scientific contribution to the study and they are thoroughly familiar with the primary data. All authors have read the complete manuscript and take responsibility for the content and completeness of it and understand that if the paper, or any part of it, is found to be faulty or fraudulent, all authors share responsibility.

Patient consent Not required.

Provenance and peer review Not commissioned; externally peer reviewed.

Data sharing statement All available data can be obtained by contacting the corresponding author.

Open Access This is an Open Access article distributed in accordance with the Creative Commons Attribution Non Commercial (CC BY-NC 4.0) license, which permits others to distribute, remix, adapt, build upon this work non-commercially, and license their derivative works on different terms, provided the original work is properly cited and the use is non-commercial. See: http://creativecommons.org/ licenses/by-nc/4.0/

(C) Article author(s) (or their employer(s) unless otherwise stated in the text of the article) 2018. All rights reserved. No commercial use is permitted unless otherwise expressly granted.

\section{REFERENCES}

1. McBeth J, Jones K. Epidemiology of chronic musculoskeletal pain. Best Pract Res Clin Rheumatol 2007;21:403-25.

2. Linaker $\mathrm{CH}$, Walker-Bone K. Shoulder disorders and occupation. Best Pract Res Clin Rheumatol 2015;29:405-23.

3. Meislin RJ, Sperling JW, Stitik TP. Persistent shoulder pain: epidemiology, pathophysiology, and diagnosis. Am J Orthop 2005;34:5-9.

4. Pribicevic M. The epidemiology of shoulder pain : a narrative review of the literature, 2012:147-85.

5. Kuijpers T, van der Windt DA, van der Heijden GJ, et al. Systematic review of prognostic cohort studies on shoulder disorders. Pain 2004;109:420-31.

6. van der Windt DA, Koes BW, Boeke AJ, et al. Shoulder disorders in general practice: prognostic indicators of outcome. Br J Gen Pract 1996;46:519-23.

7. Gatchel RJ, Peng YB, Peters ML, et al. The biopsychosocial approach to chronic pain: scientific advances and future directions. Psychol Bull 2007;133:581-624.

8. Waddell G. A new clinical model for the treatment of low-back pain. Spine 1987;12:632-44.

9. Pincus $\mathrm{T}$, Kent $\mathrm{P}$, Bronfort $\mathrm{G}$, et al. Twenty-five years with the biopsychosocial model of low back pain - is it time to celebrate? Spine 2013;38:2118-23.

10. Main CJ, Foster N, Buchbinder R. How important are back pain beliefs and expectations for satisfactory recovery from back pain? Best Pract Res Clin Rheumatol 2010;24:205-17.

11. Carroll LJ. Beliefs and expectations for recovery, coping, and depression in whiplash-associated disorders. Spine 2011;36:S250-S256.
12. Vranceanu AM, Barsky A, Ring D. Psychosocial aspects of disabling musculoskeletal pain. J Bone Joint Surg Am 2009;91:2014-8.

13. Burke AL, Mathias JL, Denson LA. Psychological functioning of people living with chronic pain: a meta-analytic review. Br J Clin Psychol 2015;54:345-60.

14. Vlaeyen JW, Linton SJ. Fear-avoidance and its consequences in chronic musculoskeletal pain: a state of the art. Pain 2000;85:317-32.

15. Leeuw M, Goossens ME, Linton SJ, et al. The fear-avoidance model of musculoskeletal pain: current state of scientific evidence. J Behav Med 2007;30:77-94.

16. Cook AJ, Brawer PA, Vowles KE. The fear-avoidance model of chronic pain: validation and age analysis using structural equation modeling. Pain 2006;121:195-206.

17. Steimer T. The biology of fear- and anxiety-related behaviors. Dialogues Clin Neurosci 2002;4:231-49.

18. Turk DC, Wilson HD. Fear of pain as a prognostic factor in chronic pain: conceptual models, assessment, and treatment implications. Curr Pain Headache Rep 2010;14:88-95.

19. Vlaeyen JW, Linton SJ. Fear-avoidance model of chronic musculoskeletal pain: 12 years on. Pain 2012;153:1144-7.

20. Henn RF, Kang L, Tashjian RZ, et al. Patients' Preoperative Expectations Predict the Outcome of Rotator Cuff Repair. J Bone Joint Surg Am 2007;89:1913-9.

21. Oh JH, Yoon JP, Kim JY, et al. Effect of expectations and concerns in rotator cuff disorders and correlations with preoperative patient characteristics. J Shoulder Elbow Surg 2012;21:715-21.

22. Chester R, Jerosch-Herold C, Lewis J, et al. Psychological factors are associated with the outcome of physiotherapy for people with shoulder pain: a multicentre longitudinal cohort study. $\mathrm{Br} J$ Sports Med 2018;52:1-8.

23. Gill TK, Shanahan EM, Taylor AW, et al. Shoulder pain in the community: an examination of associative factors using a longitudinal cohort study. Arthritis Care Res 2013;65:2000-7.

24. Kromer TO, Sieben JM, de Bie RA, et al. Influence of fearavoidance beliefs on disability in patients with subacromial shoulder pain in primary care: a secondary analysis. Phys Ther 2014;94:1775-84.

25. Reilingh ML, Kuijpers T, Tanja-Harfterkamp AM, et al. Course and prognosis of shoulder symptoms in general practice. Rheumatology 2008;47:724-30.

26. Noten $\mathrm{S}$, Struyf $\mathrm{F}$, Lluch $\mathrm{E}$, et al. Central pain processing in patients with chronic shoulder pain : a systematic literature review. Pain Pract 2016:1-14.

27. Littlewood C, Malliaras P, Bateman M, et al. The central nervous system--an additional consideration in 'rotator cuff tendinopathy' and a potential basis for understanding response to loaded therapeutic exercise. Man Ther 2013;18:468-72.

28. Chan ME, Arvey RD. Meta-analysis and the development of knowledge. Perspect Psychol Sci 2012;7:79-92.

29. Liberati A, Altman DG, Tetzlaff $\mathrm{J}$, et al. The PRISMA statement for reporting systematic reviews and meta-analyses of studies that evaluate health care interventions: explanation and elaboration. $J$ Clin Epidemiol 2009;62:e1-e34.

30. Haddaway NR, Collins AM, Coughlin D, et al. The role of google scholar in evidence reviews and its applicability to grey literature searching. PLoS One 2015;10:e0138237-17.

31. Adom T, Puoane T, De Villiers A, et al. Prevalence of obesity and overweight in African learners: a protocol for systematic review and meta-analysis. BMJ Open 2017;7:e013538.

32. Wells GA, Shea B, O'Connel D, et al. The Newcastle-Ottawa scale asses. Qual. non-randomised studies in meta-anlyses, 2009.

33. Bawor M, Dennis BB, Bhalerao A, et al. Sex differences in outcomes of methadone maintenance treatment for opioid use disorder: a systematic reviewand meta-analysis. CMAJ Open 2015;3:E344-E351.

34. Atkins D, Best D, Briss PA, et al. Grading quality of evidence and strength of recommendations. BMJ 2004;328:1490.

35. Schünemann HJ, Brozek J. GRADEpro guideline development tool. Hamilton, Canada: McMaster University, 2015.

36. George SZ, Wallace MR, Wright TW, et al. Evidence for a biopsychosocial influence on shoulder pain: pain catastrophizing and catechol-O-methyltransferase (COMT) diplotype predict clinical pain ratings. Pain 2008;136:53-61.

37. Valencia C, Fillingim RB, George SZ. Suprathreshold heat pain response is associated with clinical pain intensity for patients with shoulder pain. J Pain 2011;12:133-40.

38. Valencia C, Fillingim RB, Bishop M, et al. Investigation of central pain processing in postoperative shoulder pain and disability. Clin J Pain 2014;30:775-86. 
39. Cho $\mathrm{CH}$, Song KS, Hwang I, et al. Does rotator cuff repair improve psychologic status and quality of life in patients with rotator cuff tear? Clin Orthop Relat Res 2015;473:3494-500.

40. Cho $\mathrm{CH}$, Song KS, Hwang I, et al. Changes in psychological status and health-related quality of life following total shoulder arthroplasty. $J$ Bone Joint Surg Am 2017;99:1030-5.

41. Dekker AP, Salar O, Karuppiah SV, et al. Anxiety and depression predict poor outcomes in arthroscopic subacromial decompression. J Shoulder Elbow Surg 2016;25:873-80.

42. Jawa A, Dasti U, Brown A, et al. Gender differences in expectations and outcomes for total shoulder arthroplasty: a prospective cohort study. J Shoulder Elbow Surg 2016;25:1323-7.

43. Koorevaar RC, van 't Riet E, Gerritsen MJ, et al. The influence of preoperative and postoperative psychological symptoms on clinical outcome after shoulder surgery: a prospective longitudinal cohort study. PLoS One 2016;11:e0166555.

44. Potter MQ, Wylie JD, Granger EK, et al. One-year patient-reported outcomes after arthroscopic rotator cuff repair do not correlate with mild to moderate psychological distress. Clin Orthop Relat Res 2015;473:3501-10.

45. Razmjou H, Davis AM, Jaglal SB, et al. Disability and satisfaction after rotator cuff decompression or repair: a sex and gender analysis. BMC Musculoskelet Disord 2011;12:66.

46. Styron JF, Higuera CA, Strnad G, et al. Greater patient confidence yields greater functional outcomes after primary total shoulder arthroplasty. J Shoulder Elbow Surg 2015;24:1263-7.

47. Tokish JM, Kissenberth MJ, Tolan SJ, et al. Resilience correlates with outcomes after total shoulder arthroplasty. J Shoulder Elbow Surg 2017;26:752-6.

48. Werner BC, Wong AC, Mahony GT, et al. Causes of poor postoperative improvement after reverse total shoulder arthroplasty. J Shoulder Elbow Surg 2016;25:e217-e222.

49. Werner BC, Wong AC, Chang B, et al. Depression and patientreported outcomes following total shoulder arthroplasty. J Bone Joint Surg Am 2017;99:688-95.

50. Yeoman TFM, Wigderowitz CA. The effect of psychological status on pain and surgical outcome in patients requiring arthroscopic subacromial decompression. European Journal of Orthopaedic Surgery \& Traumatology 2012;22:549-53.

51. Ekeberg OM, Bautz-Holter E, Juel NG, et al. Clinical, sociodemographic and radiological predictors of short-term outcome in rotator cuff disease. BMC Musculoskelet Disord 2010;11:239.

52. Badcock LJ, Lewis M, Hay EM, et al. Chronic shoulder pain in the community: a syndrome of disability or distress? Ann Rheum Dis 2002;61:128-31.

53. Coronado RA, Simon CB, Lentz TA, et al. Optimism moderates the influence of pain catastrophizing on shoulder pain outcome: a longitudinal analysis. J Orthop Sports Phys Ther 2017;47:21-30.

54. Engebretsen K, Grotle M, Bautz-Holter E, et al. Predictors of shoulder pain and disability index (SPADI) and work status after 1 year in patients with subacromial shoulder pain. BMC Musculoskelet Disord 2010;11:218.
55. Karlsson L, Gerdle B, Takala EP, et al. Associations between psychological factors and the effect of home-based physical exercise in women with chronic neck and shoulder pain. SAGE Open Med 2016;4:205031211666893.

56. Macfarlane GJ, Hunt IM, Silman AJ. Predictors of chronic shoulder pain: a population based prospective study. J Rheumatol 1998;25:1612-5.

57. Burns LC, Ritvo SE, Ferguson MK, et al. Pain catastrophizing as a risk factor for chronic pain after total knee arthroplasty: a systematic review. J Pain Res 2015;8:21-32.

58. Kroska EB. A meta-analysis of fear-avoidance and pain intensity: the paradox of chronic pain. Scand J Pain 2016:13:43-58

59. Ortego G, Villafañe JH, Doménech-García V, et al. Is there a relationship between psychological stress or anxiety and chronic nonspecific neck-arm pain in adults? A systematic review and metaanalysis. J Psychosom Res 2016;90:70-81.

60. Theunissen M, Peters ML, Bruce J, et al. Preoperative Anxiety and Catastrophizing. Clin J Pain 2012;28:819-41.

61. Gross JJ. Emotion regulation: taking stock and moving forward. Emotion 2013;13:359-65.

62. Jackson $T$, Wang $Y$, Wang $Y$, et al. Self-efficacy and chronic pain outcomes: a meta-analytic review. J Pain 2014;15:800-14.

63. Martinez-Calderon J, Zamora-Campos C, Navarro-Ledesma S et al. The role of self-efficacy on the prognosis of chronic musculoskeletal pain: a systematic review. J Pain 2018;19:10-34

64. Ellis DJ, Mallozzi SS, Mathews JE, et al. The Relationship between preoperative expectations and the short-term postoperative satisfaction and functional outcome in lumbar spine surgery: a systematic review. Global Spine J 2015;5:436-51.

65. Wideman TH, Sullivan MJ. Differential predictors of the longterm levels of pain intensity, work disability, healthcare use, and medication use in a sample of workers' compensation claimants. Pain 2011;152:376-83.

66. Sullivan M, Tanzer M, Stanish W, et al. Psychological determinants of problematic outcomes following Total Knee Arthroplasty. Pain 2009;143:123-9.

67. Eccleston C, Crombez G. Pain demands attention: a cognitiveaffective model of the interruptive function of pain. Psychol Bull 1999;125:356-66.

68. Mohr DC, Ho J, Duffecy J, et al. Perceived barriers to psychological treatments and their relationship to depression. J Clin Psychol 2010;66:n/a-409.

69. Jack K, McLean SM, Moffett JK, et al. Barriers to treatment adherence in physiotherapy outpatient clinics: a systematic review. Man Ther 2010;15:220-8.

70. Picha KJ, Howell DM. A model to increase rehabilitation adherence to home exercise programmes in patients with varying levels of selfefficacy. Musculoskeletal Care 2018;16:233-7.

71. van Hecke O, Torrance N, Smith BH. Chronic pain epidemiology where do lifestyle factors fit in? Br J Pain 2013;7:209-17. 